\title{
Management of Renal Involvement in Scleroderma
}

\author{
Edward P. Stern, MBBS, MRCP \\ Virginia D. Steen, $M D^{2}$ \\ Christopher P. Denton, PhD, FRCP ${ }^{1, *}$
}

\author{
Address \\ *,1Centre for Rheumatology, University College London, UCL Royal Free Campus, \\ Rowland Hill Street, London, NW3 2PF, UK \\ Email: c.denton@ucl.ac.uk \\ Email: e.stern@ucl.ac.uk \\ ${ }^{2}$ Georgetown University, 3800 Reservoir Road, PHC 3004, Washington, DC 20007, \\ USA \\ Email: steenv@georgetown.edu
}

Published online: 8 January 2015

(C) Springer International Publishing AG 2015

This article is part of the Topical Collection on Scleroderma

Keywords Systemic sclerosis - Scleroderma - Renal crisis - Acute kidney injury · Accelerated hypertension

\section{Opinion statement}

The major renal manifestation of systemic sclerosis is scleroderma renal crisis (SRC). This condition is characterized by accelerated phase hypertension and acute kidney injury (AKI). The management of renal crisis was revolutionized by the introduction of angiotensin-converting enzyme (ACE) inhibitors more than 30 years ago, although in the current era, there is still a significant proportion of patients who have poor outcomes. Recognizing patients at high risk is a key part of the management of SRC. In particular, patients with early diffuse skin involvement from scleroderma and those who have the anti-RNA polymerase III autoantibody are at significantly increased risk for renal crisis. In these patient groups, we recommend avoidance of significant corticosteroid doses and regular home blood pressure monitoring. These measures should reduce the incidence of SRC and ensure its early diagnosis when it does appear. There is no role for ACE inhibitor prophylaxis of SRC. Patients with SRC should be hospitalized and receive careful supportive care. The condition presents with renal, hematological, and cardiac complications in the context of a complex multisystem rheumatological disease, so good inter-disciplinary care is a key goal to improve outcomes. The specific treatment for SRC remains ACE inhibitors, which should be titrated to the highest tolerated dose and continued indefinitely in all patients, regardless of renal recovery or establishment on dialysis. Other antihypertensives can be used in addition to achieve optimal blood pressure control. Patients with SRC can recover renal function after more than 2 years on dialysis, so renal transplantation should not be undertaken during this early period. 


\section{Introduction}

Systemic sclerosis (SSc) has the highest disease-related mortality of all autoimmune rheumatic conditions. In recent years, the predominant cause of death has been cardiopulmonary complications of the disease [1]. Historically, the complication of SSc associated with the highest mortality was scleroderma renal crisis (SRC), which was almost universally fatal until the late 1970s [2]. Since the development of angiotensin-converting enzyme inhibitors (ACEi), SRC has been considered a treatable complication of SSc. However, there are still many patients who do not survive or do not recover independent renal function, so improving the diagnosis and management of this medical emergency remains an important goal for rheumatologists and nephrologists.

\section{Kidney disease in systemic sclerosis}

There is a broad spectrum of renal involvement in scleroderma. Like other organs affected by SSc, the kidney is subject to chronic, progressive parenchymal fibrosis and vasculopathy. Reflecting this pathology, the prevalence of chronic kidney disease (CKD), as defined by urinary abnormalities or a reduced estimated glomerular filtration rate (eGFR), was as high as $50 \%$ in an unselected series of scleroderma patients, although slowly progressive chronic kidney disease is very uncommon (E. Kingdon, C.P. Denton Abstract 2003). In addition, other specific kidney diseases, including ANCAassociated vasculitis [3] and interstitial nephritis [4], are seen in the context of SSc. However, the most clinically significant renal manifestation in scleroderma is still SRC, and this review will concentrate on that topic.

\section{Definition of scleroderma renal crisis}

Scleroderma renal crisis is defined as the new onset of accelerated arterial hypertension and/or rapidly progressive oliguric renal failure occurring in the context of SSc. Neither hypertension nor a rise in serum creatinine in isolation can be presumed to be diagnostic of SRC. There are many other likely causes of acute kidney injury (AKI) in this patient population, and in a complex multisystem disorder, a rise in creatinine secondary to circulatory dysfunction (so-called pre-renal AKI) or drug-related causes should always be suspected. There have been some differences between the criteria used to define SRC in different studies, which may account for some of the different outcomes reported. Consensus criteria for the definition of SRC are summarized in Table 1 below [1].

\section{Pathogenesis of scleroderma renal crisis}

The pathology of SSc is typically described as a triad of autoimmunity, vasculopathy, and fibrosis, and dysfunction in all three of these three areas has been demonstrated in the kidney in patients with SSc [5]. Having said that, renal crisis is principally an impairment of arterial blood flow in the kidney.

Endothelial injury, with increased vascular permeability and subsequent intimal proliferation, is an early event in scleroderma kidney disease. The resulting luminal narrowing, particularly in the interlobular and arcuate arteries, results in reduced blood flow to the renal cortex, which is likely to be a key stage in the evolution of SRC.

In addition to endothelial injury, endothelial cell activation has been implicated in the development or progression of renal crisis. Increased circulating levels of endothelin-1 [6] and soluble vascular adhesion molecules (s-VCAM-1) [5] have been shown to be associated with SRC. Staining of SRC renal biopsies has demonstrated increased tissue concentration of ET-1 and increased expression of both subtypes of the endothelin receptor $[7,8 \bullet]$.

One chronic result of decreased renal cortical perfusion is hyperplasia of the juxtaglomerular apparatus, the major site of renin production in the kidney [9]. At the time of renal crisis, patients have marked elevation in peripheral levels of 


\section{Table 1. Diagnostic criteria for scleroderma renal crisis}

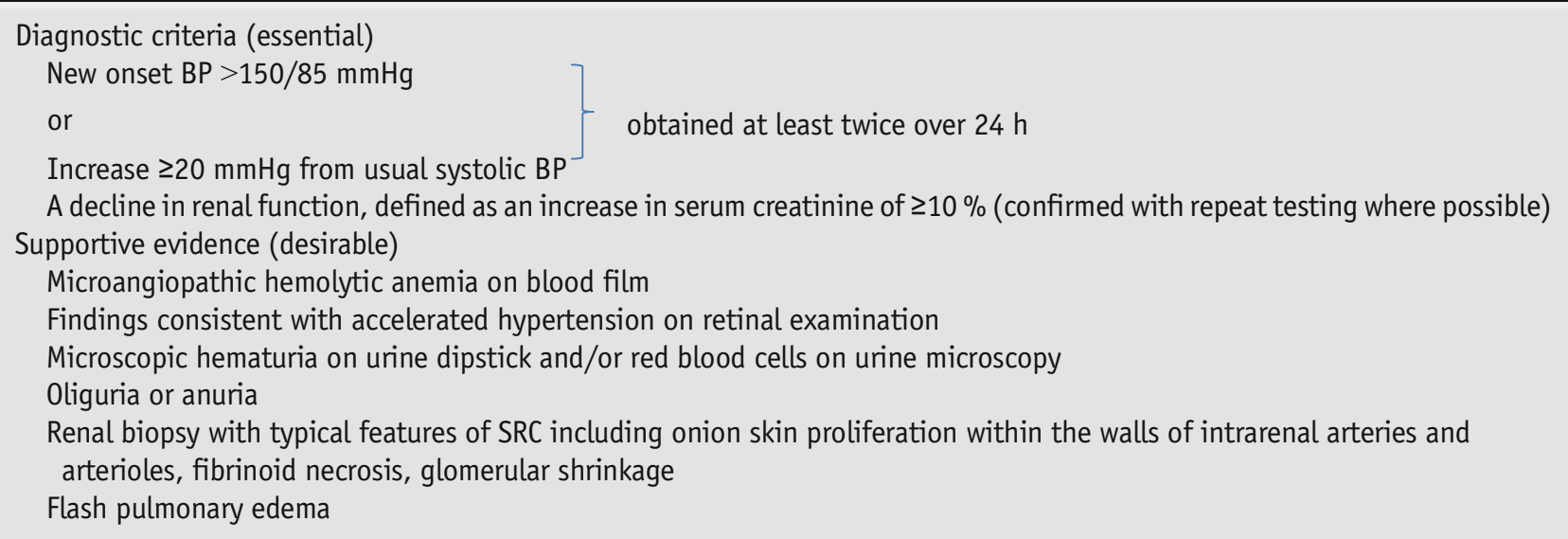

\section{Epidemiology}

renin. Given the dramatic response to therapeutic inhibition of the reninangiotensin system in SRC patients (and previously to nephrectomy), it is likely that renin overproduction has a central role in the evolution of the condition [2]. However, hyperreninemia is uncommon prior to the acute onset of SRC and when detected is not predictive of future crisis [10], so it remains unclear what precipitates the acute crisis in a subgroup of patients with renal vasculopathy.

There is no specific evidence regarding the role that autoimmunity plays in SRC, but the marked contrast between the frequency of SRC in patients with anti-centromere antibody $(<1 \%)$ and those with anti-RNA polymerase III $(33 \%)$ provides hope that a better understanding of the role these antibodies play in the pathophysiology of SSc in general will further our understanding of renal crisis specifically [11].

\section{Predicting renal crisis}

SRC is seen in around $10 \%$ of the SSc population overall and $20-25 \%$ of patients with the diffuse subtype. Seventy-five percent of SRC cases occur less than 4 years after the first symptom attributable to SSc [10], and in one renal crisis series, it was the presenting symptom of SSc for $22 \%$ of patients [12•]. Males are proportionately more likely to be affected than females [13], and in one study, African-Americans were three times as likely to be affected as Caucasians [14].

Given the predisposing factors that have been identified in SRC cohort studies, careful baseline assessment will allow us to identify patients at increased risk of renal crisis and manage them appropriately. These risk factors are summarized in Table 2. With regard to scleroderma phenotype, patients with diffuse cutaneous SSc (dcSSc) are at the greatest risk, i.e., patients with skin thickening on 
Table 2. Risk factors for scleroderma renal crisis

\author{
Increased risk of SRC \\ Disease symptoms $<4$ years \\ Diffuse skin involvement \\ Rapid progression of skin thickening \\ Anti-RNA polymerase III antibody \\ New cardiac events \\ Pericardial effusion \\ Congestive heart failure \\ New anemia \\ Recent high-dose corticosteroid exposure
}

\author{
No increased risk of SRC \\ Previous acute or chronic hypertension \\ Abnormal urinalysis \\ Preexisting chronic kidney disease \\ Pathological abnormalities of renal blood vessels \\ Anti-topoisomerase/anti-centromere antibodies
}

the proximal limbs or trunk. Of this patient subgroup, 20-25\% will develop renal crisis [15•], and they make up 75-80\% of SRC cases.

Patients who are destined to develop dcSSc but do not yet have the typical diffuse skin changes make up a further 15-20 \% of SRC cases. Identifying early diffuse patients is therefore of particular importance. These patients have usually had sclerodermatous symptoms for less than 1 year. They typically have polyarthritis/arthralgias, puffy or swollen hands and legs, and carpal tunnel syndrome [16]. Palpable tendon friction rubs can be an important clue-these occur at some point in $65 \%$ of patients with dcSSc [17] but fewer than $5 \%$ of patients with limited disease,

Autoimmune serology can also help us to identify patients at significant risk of SRC. Anti-RNA polymerase III is a scleroderma-specific antibody that is seen almost exclusively in dcSSc, and 24 to $33 \%$ of patients with this antibody develop SRC $[18,19]$. The frequency of this antibody in scleroderma in published cohorts from Asia or Southern Europe ranges from 6 to $9 \%$, so it is not surprising that these countries have a low frequency of renal crisis compared with the USA and the UK, where the frequency is of RNA polymerase III is more than $20 \%$ [18]. Renal crisis occurs in $10 \%$ of patients with anti-topoisomerase antibody, the most common antibody associated with dcSSc [20]. The anticentromere antibody, typically seen in limited cutaneous SSc, is a protective factor for renal crisis [21].

\section{Management of patients at high risk of renal crisis}

\section{Early identification}

All patients with scleroderma should have regular blood pressure monitoring together with urinalysis and serum biochemistry to detect impaired renal function. Patient education regarding the risk of renal crisis and its presentation is important, and patients should be aware of the potential presenting symptoms of accelerated hypertension, including headache, blurred vision, altered mental state, breathlessness, and palpitations.

For patients with early dcSSc (within 4 years of diagnosis), we recommend home BP monitoring twice weekly. Patients should be given individualized blood pressure targets and instructions to seek medical review if their blood pressure is above these. 
Corticosteroid exposure

Typically, patients who go on to have renal crisis do not have hypertension prior to the acute onset, and the rise in blood pressure is rapid. In cases where blood pressure is checked regularly, normal blood pressures have been seen as recently as $24 \mathrm{~h}$ prior to the diagnosis of SRC [14].

An association between corticosteroid use and the development of SRC has been described since the 1950s [22, 23]. A recent meta-analysis estimated that the incidence of SRC among patients exposed to $>15 \mathrm{mg}$ prednisolone a day or equivalent was approximately twice that is seen in the remaining SSc population [24•]. It is not easy to interpret the significance of this association. Renal crisis is most prevalent among patients with early, aggressive disease: the same group who are likely to be treated with high steroid doses. A case-control study of patients with renal crisis compared to other patients at high risk (according to the clinical risk factors described above) found that those who had received $>15 \mathrm{mg}$ prednisolone were three times as likely to be diagnosed with SRC in the following 6 months [25]. We recommend that high-dose steroids should be used with great caution and very close monitoring in patients with early dcSSc.

\section{ACE Inhibitors prior to renal crisis}

There is no evidence to support the use of ACE inhibitors as a preventative treatment in high-risk scleroderma patients, according to retrospective studies $[12 \bullet, 26 \bullet]$, and indeed this may be harmful. A recent prospective study of 75 patients with renal crisis found that those who had been on ACE inhibitors prior to the diagnosis of SRC had more than two times the risk of death in the year following SRC [27]. The authors propose several possible hypotheses for this unexpected finding. It may be that partial ACE inhibition masked the cardinal finding of hypertension at the onset of renal crisis and therefore lead to late diagnosis of these patients. It might also be that the group of patients who developed clinically detectable renal crisis despite taking an ACE inhibitor were in a resistant group with an intrinsically poor prognosis. Finally, they propose confounding by indication, i.e., that the preceding hypertension or cardiac failure for which the ACE inhibitor was prescribed was responsible for the excess mortality in these patients.

\section{Clinical presentation of SRC}

As with other causes of accelerated hypertension, patients may complain of severe headache, blurred vision, or other encephalopathic symptoms, including seizures in the most severely affected. As in other forms of AKI, patients may occasionally present with oliguria or with obviously uremic symptoms. The majority of patients will be nonspecifically unwell, complaining of increased fatigue, headache, or occasionally dyspnea. High-risk patients should be taught to take these symptoms seriously and to check their own blood pressure if they occur.

The presenting blood pressure at the onset of SRC is variable, but a large majority has significant hypertension. Ninety percent have BP levels greater than $150 / 90 \mathrm{mmHg}$, and $30 \%$ have diastolic recordings greater than $120 \mathrm{mmHg}$. A blood pressure in the normal range is seen in around $10 \%$ of cases. However, these patients usually have a significantly raised BP compared 
to their own baseline measurements. An increase of $20 \mathrm{mmHg}$ in either the systolic or diastolic pressure would be potentially diagnostic in this setting. All changes in BP in patients with SSc require further investigation and monitoring. The diagnosis of "normotensive renal crisis" requires other clinical features or investigation findings, primarily rapidly progressive unexplained AKI and/or microangiopathic hemolytic anemia (MAHA).

Patients may present with symptoms and signs secondary to hyperreninemia and accelerated hypertension, including signs of congestive cardiac failure, pericardial effusion, or arrhythmias. Fundoscopy may demonstrate grade III/IV hypertensive retinopathy.

\section{Laboratory findings}

There is usually both proteinuria and microscopic hematuria on dipstick urinalysis. Proteinuria is mild or moderate (generally $<2$ g per day), and microscopy can show granular casts [28]. Serum creatinine is typically at least $150 \%$ of baseline value at presentation. This is stage 1 acute kidney injury in the most recent international consensus guidelines for AKI care [29]. It is worth noting that in SSc patients with low muscle mass, the creatinine value will commonly reach this threshold without rising above the normal range values quoted by most laboratories. Creatinine can rise rapidly in the first few days following and will usually continue to rise even once blood pressure has been adequately controlled.

There is serological evidence of MAHA in around half of patients. One series found a reduced platelet count in $50 \%$ of SRC patients and red cell fragments in $52 \%[12 \bullet]$. Other evidence of hemolysis, including a reduced serum haptoglobin level and/or a raised lactate dehydrogenase, should be sought.

Even in a patient with obvious cutaneous signs of scleroderma, the presence of MAHA and accelerated hypertension or the findings of thrombotic microangiopathy on kidney biopsy can occasionally raise the possibility of a primary hemotological diagnosis, i.e., thrombotic thrombocytopenia purpura (TTP) or atypical hemolytic uremic syndrome (aHUS). The distinction is clinically important as plasmapheresis, the primary acute treatment for TTP or aHUS, has not been demonstrated to benefit patients with SRC. There are several reported cases of TTP and scleroderma in the literature [30-33]. Fever and hemorrhagic manifestations were the principal clinical findings that differentiated these cases from SRC. Levels of the metalloproteinase enzyme ADAMTS13, which are reduced in TTP [34], were normal in a small study of patients with SRC (K.S. Torok et al. "Scleroderma renal crisis and thrombotic thrombocytopenic purpura-are they related," American College of Rheumatology abstract 2008). However, in most institutions, results of the ADAMTS13 assay will not be available early enough to affect the immediate clinical management. Given the remaining diagnostic uncertainty in this field, if a diagnosis of TTP or HUS is suspected in a scleroderma patient, we recommend that an ACE inhibitor should be used in conjunction with plasmapheresis.

Renal ultrasound is typically unremarkable in SRC but may be useful in some patients to rule out urinary tract obstruction as a cause of AKI. 


\section{Renal pathology}

Echocardiography can show pericardial effusions and left ventricular systolic dysfunction, which are common findings secondary to the increased afterload on the heart. Signs of pulmonary hypertension are sometimes seen on echo, but in the SRC cohort, this is almost always a transient secondary phenomenon caused by accelerated hypertension rather than chronic pulmonary arterial hypertension.

In the acute setting, the main diagnostic benefit of renal biopsy is to exclude other pathologies. In the longer term, it may help to inform renal prognosis (see below). Biopsy needs to be delayed until the patient is clinically stable with good blood pressure control and the platelet count has recovered.

The renal pathological findings in SRC are broadly the same as those seen in other causes of accelerated hypertension [4]. Fibrinoid necrosis is seen either in arterial walls or in the subintima in small arteries and arterioles (characteristically the interlobular and arcuate arteries). The resulting intimal thickening leads to narrowing or total obliteration of the lumen and a typical "onion skin" appearance (Fig. 1). Adventitial and peri-adventitial fibrosis, an indication of chronic vasculopathy seen in patients with SRC, is rarely seen in accelerated hypertension without scleroderma. Glomeruli are collapsed with wrinkling of the basement membrane. Interestingly, unlike in other renal diseases, the extent of interstitial scarring does not have prognostic value, whereas markers of acute vascular injury (including fibrinoid necrosis and thrombosed vessels) do predict poor renal outcome $[4,12 \bullet]$.

\section{Treatment}

Patients with SRC are in a high mortality group and need aggressive inpatient management. In addition to close monitoring and renal replacement therapy (RRT) when required, higher level care of the unwell patient with renal crisis might include ventilatory support, where there is severe pulmonary edema, and sedation or anti-seizure medications for hypertensive encephalopathy.

Immediately on diagnosis of SRC, an ACEi should be introduced or the dose increased if the patient is already taking one [35]. A short-acting ACE inhibitor (e.g., captopril) may be preferable in a hemodynamically unstable patient, but there is no evidence that it is preferable in general to a once-daily medication. ACEi resistance is more typical than oversensitivity, and our practice is to initiate a long-acting drug as soon as possible and escalate the dose daily to maximum. We recommend that any rise in serum creatinine after increasing ACEi dose should not trigger dose reduction or ACEi cessation. There is no evidence in scleroderma renal crisis that renal function can be spared or improved by minimizing ACEi dose. The eventual goal is to reach the pre-SRC blood pressure, but in the absence of hypertensive encephalopathy or cardiac 


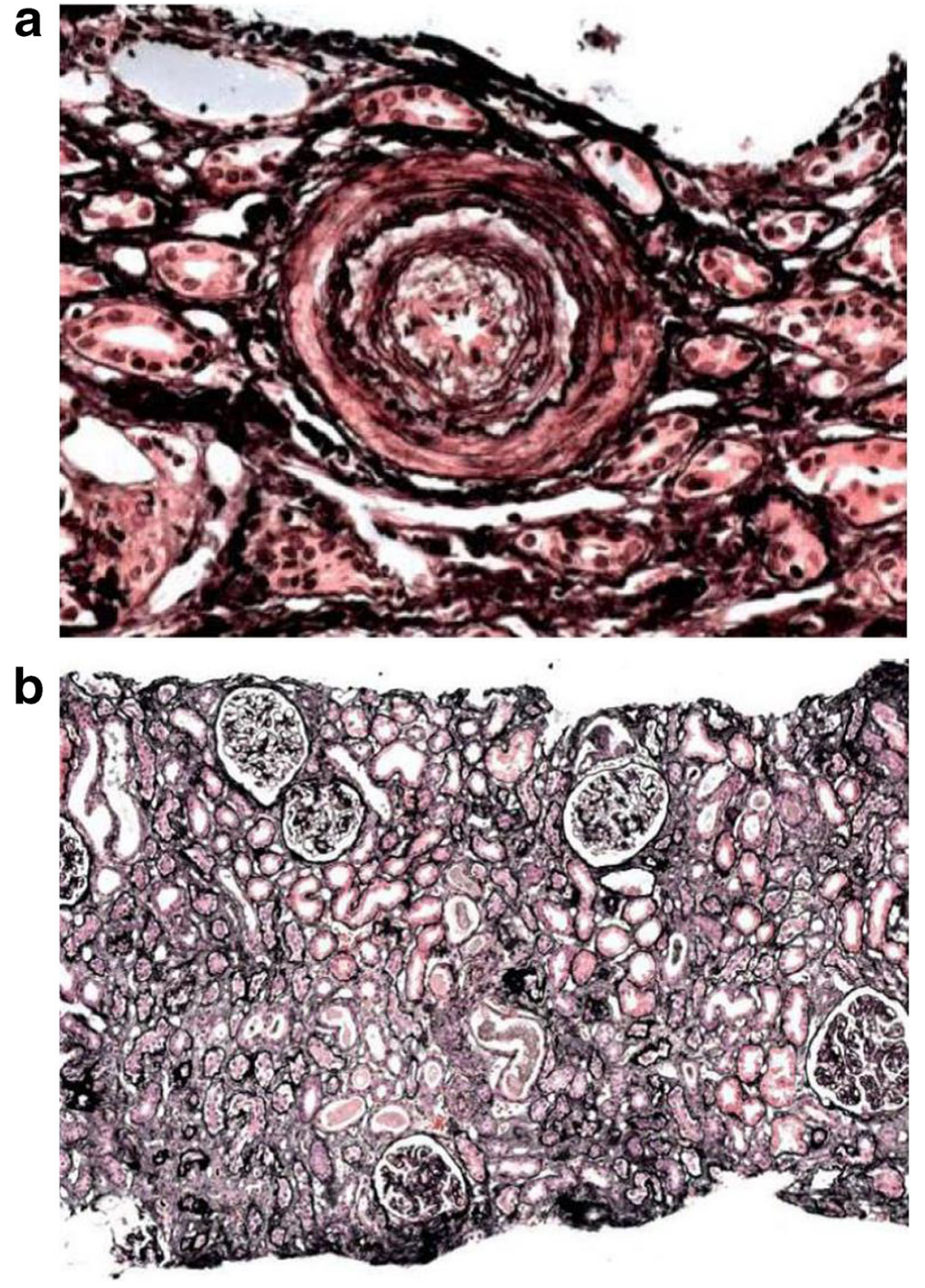

Fig. 1. Renal biopsy findings in SRC. a An interlobular artery showing, loose, concentric intimal thickening superimposed on a ring of smooth muscle inside the internal elastic lamina. This suggests a recent acute vascular injury superimposed on a chronic vasculopathy. b Cortex in a kidney affected by SRC. Glomeruli show acute ischemic shrinkage. Tubules show acute ischemic damage and early atrophy.

decompensation, a steady reduction in the blood pressure of around $10 \%$ per day is preferable to dropping it precipitously.

Given the dramatic survival benefit conferred by antagonizing one part of the renin-angiotensin system (RAS) in SRC, we might be optimistic about the benefits of blocking other parts of this endocrine axis. There are reports suggesting that angiotensin receptor blockers (ARBs) alone are less effective that ACEi in treating SRC $[36,37]$. There is no evidence regarding the role of direct renin inhibitors. Our practice is to add an ARB to treatment once the ACEi is in the therapeutic range and to introduce other antihypertensives including calcium channel blockers, doxazosin and clonidine if blood pressure remains above the target on ACEi and ARB combination therapy. Beta-blocking drugs are 
contraindicated in SRC due to effects on peripheral circulation and intravenous antihypertensives are not usually indicated, although nitrate infusion is sometimes required when pulmonary edema complicates SRC.

\section{Endothelin receptor antagonists (ERAs)}

Endothelin receptor antagonists have been demonstrated to have significant outcome benefit in both PAH and digital ulceration in patients with SSc. This has raised the question of their utility in renal crisis, another vasculopathic manifestation of SSc, and this drug type has been used in selected scleroderma patients with renal crisis [38]. As discussed above, high circulating levels of ET-1 and upregulation of the endothelin receptor have been demonstrated in SRC. Polymorphism in the endothelin ligand receptor axis has been associated with SRC [39], whereas polymorphism in the ACE axis has not [40], so it is possible that activation of the endothelin system is a key event in the evolution of the condition. In a recent open label pilot study, the nonselective ERA bosentan was given to six patients with SRC. Although not significant, there was a trend towards lower rates of dialysis and better recovery of renal function in these patients $[8 \bullet$. At least two further studies of this drug class in SRC are ongoing.

Other drug treatments

The prostacyclin analogue Iloprost is an additional way to reduce the systemic vascular resistance in SRC and has been shown specifically to increase blood flow within the kidney in patients with SSc [41]. The role of immunosuppression in the context of acute SRC has not been defined.

\section{Renal replacement therapy}

In the US and UK case series since the advent of ACEi, the number of SRC patients who progressed to needing RRT was around $60 \%$ compared to $>90 \%$ prior to the availability of ACEi [12•,42]. The most commonly used form of RRT in the acute phase is intermittent hemodialysis (HD), but continuous hemofiltration is occasionally required for patients with marked hemodynamic instability. In the general chronic RRT population, peritoneal dialysis (PD) is associated with better preservation of residual renal function than HD [43, 44], and this may be a particular consideration in the SRC group, given the potential for late recovery of renal function. PD in this patient group is not uncommon - in a case series which included all patients with scleroderma who received RRT in Australia or New Zealand between 1963 and 2005, 50 \% of patients had PD [45], Despite this, there are currently no data directly comparing outcomes of PD and HD after renal crisis.

Recovery of renal function can continue for months or years after SRC and ACEi therapy should be continued indefinitely in all patients, whether or not they are on dialysis. In the US and UK case series described above, close to $50 \%$ of patients initiated on RRT later recovered independent renal function to discontinue dialysis. In the UK series, the median time to becoming dialysis independent was 11 months (range 1-34 months) [12•]. In a large majority of both those who did not require dialysis and those who had temporary dialysis, eGFR continued to improve for at least 3 years after SRC diagnosis (see prognosis below). 


\section{Prognosis}

Because of the possibility of late recovery of renal function, renal transplantation should not be undertaken for at least 12 months after the diagnosis of renal crisis. Calcineurin inhibitors (cyclosporine and tacrolimus) are renal vasoconstrictors and are associated with an increased risk of SRC [46, 47], so the choice of immunosuppressive regimen also needs careful consideration in this group of patients. There are case reports of recurrence of SRC both early and later after renal transplantation $[37,48]$, but overall, renal transplant improved survival in scleroderma compared to those who remained on dialysis [49].

\section{Mortality}

Prior to the use of ACE inhibitors, survival to 1 year in a patient with SRC was a rare event $[14,15 \bullet]$. After ACEi use became widespread in the early 1980s, there was a dramatic improvement seen. Patients who "survive" renal crisis without the need for dialysis or only temporary dialysis have excellent outcomes with 5year survival of $90 \%$ [42]. However, we still have $40-50 \%$ of patients who have a bad outcome with early deaths or permanent dialysis with all its problems. Reflecting these two cohorts, reviews that have looked at SRC outcome in this era have shown 5 -year survival ranging between 50 and $70 \%[12 \bullet, 26 \bullet, 27 \bullet, 50$, 51]. Sadly, there is no clear trend towards improvement in these outcomes over the past 30 years. Risk factors for mortality in these studies included male sex, older age, and lower blood pressure at the time of diagnosis as well as the development of congestive cardiac failure.

Fifty-five of the 145 patients in Steen's series did not require RRT in the acute phase. Mean peak serum creatinine among these patients was $3.8 \mathrm{mg} / \mathrm{dl}$ $(336 \mu \mathrm{mol} / \mathrm{L})$. Seven years after diagnosis of SRC, their mean creatinine was $1.8 \mathrm{mg} / \mathrm{dl}(159 \mu \mathrm{mol} / \mathrm{L})$. None went on to require RRT at a later stage. Thirty-four patients in the series had temporary dialysis. Their mean serum creatinine 6 years after SRC was $2.2 \mathrm{mg} / \mathrm{dl}(194 \mu \mathrm{mol} / \mathrm{L})$. Two of these 34 patients progressed to end-stage renal failure requiring RRT within the follow-up period [42].

\section{Survival on renal replacement therapy}

The Australia and New Zealand series quoted above showed a median survival of 2.4 years for scleroderma patients on dialysis compared with 6.0 years for other patients [45]. In a US study of dialysis patients with scleroderma between 1992 and 1997, 2-year survival in the scleroderma group was $49 \%$ compared with $64 \%$ in all other patients [52]. Likewise, a review of scleroderma renal transplant cases from the United Network for Organ Sharing registry from 1987 to 1996 showed both lower graft and patient survival times than in renal transplant patients without systemic diseases [53].

\section{Summary}

Despite the marked improvement in outcome for the majority of patients with scleroderma renal crisis since the introduction of ACE inhibitors, there is a significant subgroup for whom mortality remains high. 
Our ability to identify a subset of patients at high risk of developing the condition-those with early diffuse cutaneous systemic sclerosis in particular-offers hope that early diagnosis will improve this poor prognosis.

Recent important developments in this field include increasing evidence of the role of corticosteroids as a risk factor for SRC and recognition that ACE inhibitor prophylaxis is unlikely to be beneficial for high-risk patients. Potential new treatments for patients with renal crisis include endothelin receptor antagonists.

\section{Compliance with Ethics Guidelines}

\section{Conflict of Interest}

Edward P. Stern and Virginia D. Steen declare that they have no conflict of interest.

Christopher Denton reports grants and personal fees from Actelion pharmaceuticals, personal fees from GSK, personal fees from Genetech-Roche, and grants from Astra Zeneca, outside the submitted work.

\section{Human and Animal Rights and Informed Consent}

This article does not contain any studies with human or animal subjects performed by any of the authors.

\section{References and Recommended Reading}

Papers of particular interest, published recently, have been highlighted as:

- Of importance

1. Steen VD, Mayes MD, Merkel PA. Assessment of kidney involvement. Clin Exp Rheumatol. 2003;21(3 Suppl 29):S29-31.

2. Cannon PJ, Hassar M, Case DB, Casarella WJ, Sommers SC, LeRoy EC. The relationship of hypertension and renal failure in scleroderma (progressive systemic sclerosis) to structural and functional abnormalities of the renal cortical circulation. Medicine (Baltimore). 1974;53(1):1-46.

3. Arnaud L, Huart A, Plaisier E, Francois H, Mougenot B, Tiev K, et al. ANCA-related crescentic glomerulonephritis in systemic sclerosis: revisiting the "normotensive scleroderma renal crisis". Clin Nephrol. 2007;68(3):165-70.

4. Batal I, Domsic RT, Shafer A, Medsger TA, Kiss LP, Randhawa $\mathrm{P}$, et al. Renal biopsy findings predicting outcome in scleroderma renal crisis. Hum Pathol. 2009;40(3):332-40.

5. Stratton RJ, Coghlan JG, Pearson JD, Burns A, Sweny P, Abraham DJ, et al. Different patterns of endothelial cell activation in renal and pulmonary vascular disease in scleroderma. QJM. 1998;91(8):561-6.

6. Kobayashi H, Nishimaki T, Kaise S, Suzuki T, Watanabe K, Kasukawa R. Immunohistological study endothelin1 and endothelin-A and B receptors in two patients with scleroderma renal crisis. Clin Rheumatol. 1999;18(5):425-7.

7. Mouthon L, Mehrenberger M, Teixeira L, Fakhouri F, Bérezné A, Guillevin L, et al. Endothelin-1 expression in scleroderma renal crisis. Hum Pathol.

2011;42(1):95-102.

8. Penn H, Quillinan N, Khan K, Chakravarty K, Ong V, Burns A, et al. Targeting the endothelin axis in scleroderma renal crisis: rationale and feasibility. QJM. 2013 May 21.

A proof-of-concept trial of an endothelin receptor antagonist in scleroderma renal crisis. This drug class has the potential to be the first significant new drug treatment in SRC since the introduction of ACE-inhibitors more than 30 years ago.

9. Stone RA, Tisher CC, Hawkins HK, Robinson RR. Juxtaglomerular hyperplasia and hyperreninemia in progressive systemic sclerosis complicated acute renal failure. Am J Med. 1974;56(1):119-23.

10. Steen VD, Medsger TA, Osial TA, Ziegler GL, Shapiro AP, Rodnan GP. Factors predicting development of renal involvement in progressive systemic sclerosis. Am J Med. 1984;76(5):779-86.

11. Steen VD. Autoantibodies in systemic sclerosis. Semin Arthritis Rheum. 2005;35(1):35-42.

12. Penn H, Howiea J, Kingdon EJ, Bunn CC, Stratton RJ, Black CM, et al. Scleroderma renal crisis: patient 
characteristics and long-term outcomes. QJM. 2007;100(8):485-94.

A large cohort studydescribing the clinical presentation, pathological findings and outcomes of 110 cases of SRC in a single centre.

13. Steen VD, Lanz JK, Conte C, Owens GR, Medsger TA. Therapy for severe interstitial lung disease in systemic sclerosis. A retrospective study. Arthritis Rheum. 1994;37(9):1290-6.

14. Traub YM, Shapiro AP, Rodnan GP, Medsger TA, McDonald RH, Steen VD, et al. Hypertension and renal failure (scleroderma renal crisis) in progressive systemic sclerosis. Review of a 25-year experience with 68 cases. Medicine (Baltimore). 1983;62(6):335-52.

15. Steen VD, Costantino JP, Shapiro AP, Medsger TA. Outcome of renal crisis in systemic sclerosis: relation to availability of angiotensin converting enzyme (ACE) inhibitors. Ann Intern Med. 1990;113(5):352-7.

A prospective study 108 patients diagnosed with SRC between 1972 and 1987. Defined the dramatic reduction in mortality and morbidity associated with ACE-inhibitors.

16. LeRoy EC, Black C, Fleischmajer R, Jablonska S, Krieg T, Medsger TA, et al. Scleroderma (systemic sclerosis): classification, subsets and pathogenesis. J Rheumatol. 1988;15(2):202-5.

17. Steen VD, Medsger TA. The palpable tendon friction rub: an important physical examination finding in patients with systemic sclerosis. Arthritis Rheum. 1997;40(6):1146-51.

18. Okano Y, Steen VD, Medsger TA. Autoantibody reactive with RNA polymerase III in systemic sclerosis. Ann Intern Med. 1993;119(10):1005-13.

19. Bunn CC, Denton CP, Shi-Wen X, Knight C, Black CM. Anti-RNA polymerases and other autoantibody specificities in systemic sclerosis. Br J Rheumatol. 1998;37(1):15-20.

20. Steen VD, Medsger TA. Epidemiology and natural history of systemic sclerosis. Rheum Dis Clin N Am. 1990;16(1):1-10.

21. Steen VD, Ziegler GL, Rodnan GP, MedsgerTA. Clinical and laboratory associations of anticentromere antibody in patients with progressive systemic sclerosis. Arthritis Rheum. 1984;27(2):125-31.

22. LUNSETH JH, BAKER LA, SHIFRIN A. Chronic scleroderma with acute exacerbation during corticotropin therapy; report of a case with autopsy observations. AMA Arch Intern Med. 1951;88(6):783-92.

23. SHARNOFF JG, CARIDEO HL, STEIN ID. Cortisonetreated scleroderma; report of a case with autopsy findings. J Am Med Assoc. 1951;145(16):1230-2.

24. Trang G, Steele R, Baron M, Hudson M. Corticosteroids and the risk of scleroderma renal crisis: a systematic review. Rheumatol Int. 2012;32(3):645-53.

A systematic review and meta-analysis. Confirms the observed association between corticosteroid exposure and subsequent renal crisis.

25. Steen VD, Medsger TA. Case-control study of corticosteroids and other drugs that either precipitate or protect from the development of scleroderma renal crisis. Arthritis Rheum. 1998;41(9):1613-9.

26. Guillevin L, Bérezné A, Seror R, Teixeira L, Pourrat J, Mahr A, et al. Scleroderma renal crisis: a retrospective multicentre study on 91 patients and 427 controls. Rheumatology (Oxford). 2012;51(3):460-7.

The largest case series of SRC patients ouside the US or UK (91 French patients). The authors confirm the continuing high mortality associated with SRC compared with patients with SSC and no renal crisis.

27. Hudson M, Baron M, Tatibouet S, Furst DE, Khanna D. Exposure to ACE inhibitors prior to the onset of scleroderma renal crisis-results from the International Scleroderma Renal Crisis Survey. Semin Arthritis Rheum. 2014;43(5):666-72.

A prospective, international study which followed 75 patients with renal crisis from diagnsois to 1 year. A key finding was the association between antecedent ACE-inhibitor use and poor outcome.

28. Penn H, Denton CP. Diagnosis, management and prevention of scleroderma renal disease. Curr Opin Rheumatol. 2008;20(6):692-6.

29. KDIGO. Clinical practice guideline for acute kidney injury (AKI). Kidney Int Suppl. 2012;2(1):4.

30. Yusin J, Lewin K, Clements P. Thrombotic thrombocytopenia purpura in a patient with systemic sclerosis. J Clin Rheumatol. 2001;7(2):106-11.

31. Kapur A, Ballou SP, Renston JP, Luna E, Chung-Park M. Recurrent acute scleroderma renal crisis complicated by thrombotic thrombocytopenic purpura. J Rheumatol. 1997;24(12):2469-72.

32. Manadan AM, Harris C, Block JA. Thrombotic thrombocytopenic purpura in the setting of systemic sclerosis. Semin Arthritis Rheum. 2005;34(4):683-8.

33. Abudiab M, Krause ML, Fidler ME, Nath KA, Norby SM. Differentiating scleroderma renal crisis from other causes of thrombotic microangiopathy in a postpartum patient. Clin Nephrol. 2013;80(4):293-7.

34. Lian EC-Y. Pathogenesis of thrombotic thrombocytopenic purpura: ADAMTS13 deficiency and beyond. Semin Thromb Hemost. 2005;31(6):625-32.

35. Kowal-Bielecka O, Landewé R, Avouac J, Chwiesko S, Miniati I, Czirjak L, et al. EULAR recommendations for the treatment of systemic sclerosis: a report from the EULAR Scleroderma Trials and Research group (EUSTA R). Ann Rheum Dis. 2009;68(5):620-8.

36. Caskey FJ, Thacker EJ, Johnston PA, Barnes JN. Failure of losartan to control blood pressure in scleroderma renal crisis. Lancet. 1997;349(9052):620.

37. Cheung WY, Gibson IW, Rush D, Jeffery J, Karpinski M. Late recurrence of scleroderma renal crisis in a renal transplant recipient despite angiotensin II blockade. Am J Kidney Dis. 2005;45(5):930-4.

38. Izzedine H, Rouvier P, Deray G. Endothelin receptor antagonism-based treatment for scleroderma renal crisis. Am J Kidney Dis. 2013; 12.

39. Fonseca C, Lindahl GE, Ponticos $M$, Sestini P, Renzoni EA, Holmes AM, et al. A polymorphism in the CTGF 
promoter region associated with systemic sclerosis. N Engl J Med. 2007;357(12):1210-20.

40. Wipff J, Gallier G, Dieude P, Avouac J, Tiev K, Hachulla $\mathrm{E}$, et al. Angiotensin-converting enzyme gene does not contribute to genetic susceptibility to systemic sclerosis in European Caucasians. J Rheumatol. 2009;36(2):337-40.

41. Scorza R, Rivolta R, Mascagni B, Berruti V, Bazzi S, Castagnone $\mathrm{D}$, et al. Effect of iloprost infusion on the resistance index of renal vessels of patients with systemic sclerosis. J Rheumatol. 1997;24(10):1944-8.

42. Steen VD. Long-term outcomes of scleroderma renal crisis. Ann Intern Med Am Coll Phys. 2000;133(8):600.

43. Moist LM, Port FK, Orzol SM, Young EW, Ostbye T, Wolfe RA, et al. Predictors of loss of residual renal function among new dialysis patients. J Am Soc Nephrol. 2000;11(3):556-64.

44. Jansen MAM, Hart AAM, Korevaar JC, Dekker FW, Boeschoten EW, Krediet RT. Predictors of the rate of decline of residual renal function in incident dialysis patients. Kidney Int. 2002;62(3):1046-53.

45. Siva B, McDonald SP, Hawley CM, Rosman JB, Brown FG, Wiggins KJ, et al. End-stage kidney disease due to scleroderma-outcomes in 127 consecutive ANZDATA registry cases. Nephrol Dial Transplant. 2011;26(10):3165-71.

46. Denton CP, Sweny P, Abdulla A, Black CM. Acute renal failure occurring in scleroderma treated with cyclosporin A: a report of three cases. Br J Rheumatol. 1994;33(1):90-2.

47. Nunokawa T, Akazawa M, Yokogawa N, Shimada K, Hiramatsu K, Nishio Y, et al. Late-onset scleroderma renal crisis induced by tacrolimus and prednisolone: a case report. Am J Ther. 2012;21(5):e130-3.

48. Pham P-TT, Pham P-CT, Danovitch GM, Gritsch HA, Singer J, Wallace WD, et al. Predictors and risk factors for recurrent scleroderma renal crisis in the kidney allograft: case report and review of the literature. Am J Transplant. 2005;5(10):2565-9.

49. Gibney EM, Parikh CR, Jani A, Fischer MJ, Collier D, Wiseman AC. Kidney transplantation for systemic sclerosis improves survival and may modulate disease activity. Am J Transplant. 2004;4(12):2027-31.

50. Teixeira L, Mouthon L, Mahr A, Berezné A, Agard C, Mehrenberger $\mathrm{M}$, et al. Mortality and risk factors of scleroderma renal crisis: a French retrospective study of 50 patients. Ann Rheum Dis. 2008;67(1):110-6.

51. Walker JG, Ahern MJ, Smith MD, Coleman M, Pile K, Rischmueller M, et al. Scleroderma renal crisis: poor outcome despite aggressive antihypertensive treatment. Intern Med J. 2003;33(5-6):216-20.

52. Abbott KC, Trespalacios FC, Welch PG, Agodoa LYC. Scleroderma at end stage renal disease in the United States: patient characteristics and survival. J Nephrol. 2002;15(3):236-40.

53. Chang YJ, Spiera H. Renal transplantation in scleroderma. Medicine (Baltimore). 1999;78(6):382-5. 